\title{
Digital Economic Development and Its Impact on Econimic Growth in China: Research Based on the Prespective of Sustainability
}

\author{
Shuaitao Jiao * and Qiubi Sun *
}

check for

updates

Citation: Jiao, S.; Sun, Q. Digital Economic Development and Its Impact on Econimic Growth in China: Research Based on the Prespective of Sustainability. Sustainability 2021, 13, 10245. https://doi.org/ $10.3390 /$ su131810245

Received: 10 August 2021 Accepted: 10 September 2021 Published: 14 September 2021

Publisher's Note: MDPI stays neutral with regard to jurisdictional claims in published maps and institutional affiliations.

Copyright: (c) 2021 by the authors. Licensee MDPI, Basel, Switzerland. This article is an open access article distributed under the terms and conditions of the Creative Commons Attribution (CC BY) license (https:/ / creativecommons.org/licenses/by/ $4.0 /)$.
School of Economics \& Management, Fuzhou University, Fuzhou 350108, China

* Correspondence: N180710024@fzu.edu.cn (S.J.); sunqiubi@126.com (Q.S.)

\begin{abstract}
At present, there is a consensus that the digital economy provides a new impetus for sustainable economic development. Based on domestic and foreign literature reviews, this paper focuses on representative industry sectors; we present China's 2011-2018 digital economy development index, for 173 cities, from a three-level perspective-internet development, digital literacy, and industrial efficiency improvement. Various models, such as the instrumental variable method, the double difference method, the intermediary effect model, and the spatial econometric model were used to quantitatively analyze the impact of digital economic development on urban economic growth in China. The study finds that: (1) digital economic development in China has a positive effect on urban economic growth, and a heterogeneity of effects exists between different cities. (2) Urban employment is the "effect mechanism" of digital economic growth on urban economic growth. (3) The direct effect of digital economic development on urban economic growth in China is positive, the spillover effect is positive, the direct effect is greater than the spillover effect, and the total effect is positive. The research results enrich the measurement methods used in urban digital economic development in China, providing new perspectives for studying the influence mechanisms of digital economic development on urban economic growth.
\end{abstract}

Keywords: digital economy development; economic growth; effect mechanism; spillover effect; sustainable development

\section{Introduction}

Sustainable models of economic growth are increasingly becoming inseparable from digital technology in countries worldwide. The digital economy provides a new impetus and direction for the sustainability of economic growth. In March 2017, for the first time, content focusing on the "digital economy" appeared in a report by the Chinese government. Moreover, a report from 2019 proposed to "increase the construction of a new generation of information technology industry clusters, and continue to strengthen the research and development and application of the information technology". A 2020 government work report pointed out the need to deepen the contribution of "Internet +" technology in regard to the development of the digital economy. In 2021, the "fourteenth five-year plan for the national economic and social development of the People's Republic of China and the outline of long-term goals for 2035" quantitatively outlined a target to increase the added value of China's digital economy core industries. The above-mentioned indicate that China, at a national (and strategic) level, attaches great importance to digital economy development.

The digital economy has a "boosting" effect on sustainable economic development. Maintaining an appropriate economic growth rate is also an inevitable requirement for high-quality economic and social development. Thus, can the development of the digital economy promote urban economic growth? What are the mechanisms? and what are the impacts on economic growth? Does the development of the digital economy have heterogenetic effects on urban economic growth? Does the development of the digital 
economy have spatial characteristics and laws for urban economic growth? The answers to these questions are based on the establishment of a suitable comprehensive evaluation system for the digital economy. Research on the digital economy is still in its infancy, and its related concept definition, statistical classification, calculation, and comprehensive evaluation index system, are not mature enough. Therefore, there are relatively few theoretical studies and mechanism tests on digital economic development and urban economic growth.

Thus, based on the economic data from 173 cities in China, from 2011 to 2018, this paper used a variety of models to study the impact of digital economic development on economic growth in China. This paper is structured as follows. In Section 2, we introduce the literature review, namely the construction of the digital economy index, the sustainable and economic impacts of the digital economy, and empirical research on the digital economy. In Section 3, we present a series of theoretical analyses and theoretical hypotheses, including the background of the development of the digital economy, a theoretical mechanism analysis, and a theoretical analysis of spatial spillover effects. In Section 4, we describe the research design, namely the fixed effects model, the instrumental variable method, double difference, the mediating effect model, and the spatial econometric model, which were used as empirical research. Data sources and a summary analysis are also introduced. In Section 5, we present the results and discussion. In Section 6, we present the conclusion.

\section{Literature Review}

There are three types of literature related to the theme of this paper: first, the construction of a digital economy development index; second, the sustainable economic impact of the digital economy; third, empirical research on the development of a digital economy.

\subsection{The Construction of Digital Economy Index}

The measurement and analysis of a digital economy are critical in national economic accounting [1-3]. The main index evaluation systems include the European Union (EU) digital economy and society index (DESI), the Organization for Economic Cooperation and Development (OECD) digital economy indicator system, the World Economic Forum (WEF) network readiness index (NRI), etc. [4,5]. In China, the main index evaluation systems are the digital economy Index (DEI) of the China information and communication research institute and the China digital economy index (CDEI) of the Caixin think tank [6]. Many scholars worldwide have conducted research on the digital economy development index. Herrador and Hernandez analyzed the impact of digital information and communication technology (ICT) on accounting education [7]. Fidan used the Gini method to determine intersectoral digital economic development in Turkey and Lithuania [8]. Gravili et al. examined the impact of the digital divide and digital alphabetization on big data generation from the perspective of value creation [9]. Coyle and Nguyen noted that the revolution of economic digitalization posed a serious challenge to the traditional concept and practice of economic measurement [10]. Skliarov and Prokopov noted that the development of a digital economy would transform the traditional economy from a resource-consuming economy to a resource-creating economy [11]. Fayyaz described the exponential growth of such e-commerce in Iran and analyzed the contribution of digital e-commerce to economic growth [12]. Otioma et al. analyzed the difference of digital economy development in Kigali from a macro-spatial level [13]. Stavytskyy et al. used the digital economic and social index to study the effects of purchasing power parity and unemployment on consumption index growth in 28 European countries, from 2013 to 2018 [14]. Mirolyubova et al. noted that a digital economy development system should be built from the following indicators, namely, the cost of ICT, the number and share of employment in the digital economy, the quantity and share of digital production in the economy, the digital workforce, and digital productivity [15]. The establishment of the international index system has laid a foundation for the construction of a digital economic comprehensive evaluation system in China. However, due to the differences of industrial development levels, industrial 
policies, and comprehensive national power in different cities above prefecture level, they lead to the city digital economy comprehensive evaluation system to be different. in different countries.

\subsection{The Sustainable and Economic Impact of the Digital Economy}

The development of a digital economy will have a major impact on the sustainable development of an economy and society [16]. The development of a digital economy would have a boosting effect on the development of a regional economy, but the development of the digital economy would bring about a huge digital divide [17,18]. Antonelli used a comparative approach to assess "gaps" in regard to countries taking advantage of new technologies, and concluded that the digital revolution was creating a global digital divide [19]. By using the 2001 national census data of Australia, Gibson found that the digital divide in Australia had strong hierarchical and spatial characteristics [20]. Using data from surveys of the Dutch population, Van et al. concluded that social inequality will become more pronounced as the internet matures [21]. Karar noted that the digital divide was an extension of global inequality in Ghana and Kenya [22]. Lai et al. explained that there was a gap in internet access and speed between rural and urban areas in Indiana [23]. Apriliyanti et al. analyzed the digital divide in e-governments among members of the association of Southeast Asian nations [24]. Rodicio-Carcia et al. analyzed the digital divide in distance learning between students from different regions during COVID-19 [25]. Cortelyou-Ward et al. analyzed the great digital gap in the process of rural resident access to telemedicine [26]. Murthy et al. noted that the global digital economy was dominated by developed economies; in particular, in the area of e-commerce, the digital divide between countries was obvious [27]. Garcia and Rodrigues discussed the impact of the COVID-19 pandemic on education for the elderly [28]. Through the above-mentioned literature analysis, and with the development of the digital economy, the phenomenon of a digital economic gap widely exists.

\subsection{The Empirical Research on the Digital Economy}

In recent years, researchers have focused on theoretical and practical issues of the digital economy, but empirical research-evaluating the impact of the digital economy on economic growth-is still in its infancy [29]. However, experts and scholars generally believe that the development of the digital economy has a boosting effect on economic growth [30]. The internet and innovative industries have contributed to China's past economic growth [31,32]. Cardona et al. used empirical methods to research and analyze the role of the digital economy in promoting productivity [33]. Frey noted that the development of the digital economy could provide sustainable development momentum for economic growth [34]. Knight emphasized that a stronger interaction among physical, digital, and knowledge accessibility at the regional level will generate economic growth [35]. Chakpitak et al. used the stochastic frontier model to model the production function, and they used the model to study how the growth of digital technology affected the Thai economy [36]. Martin and Bodanac introduced the Cobb-Douglas model for using information and communications technology (ICT) to support local economic development in post-conflict environments; they conducted theoretical demonstrations using the literature on ICT in peacekeeping and economic development [37]. Hawash and Lang empirically studied the impact of ICT on the total factor productivity of developing countries, and noted that countries with higher ICT investments tend to have higher total factor productivities [38]. Vu et al. believe that the time to study the relationship between ICT and economic growth is ripe, and that research should shift from proving the positive relationship between ICT and economic growth to how emerging digital technologies directly or indirectly affect economic performance [39]. Solomon and van Klyton researched and analyzed the impact of the use of digital technology on economic growth in 39 African countries, from 2012 to 2016 [40]. Qian et al. noted that the digital economy promotes regional economic growth in China by promoting regional entrepreneurship and innovation [41]. From the 
above analyses, one may conclude that the digital economy or digital ICT can promote economic growth.

\section{Theoretical Analysis and Theoretical Hypothesis}

\subsection{The Background of the Development of the Digital Economy}

The digital economy is the main economic "form" that follows the agricultural economy and the industrial economy. Digital transformation drives changes in production methods, lifestyles, and governance. Digital transformation also has a profound impact on the world's economic, political, and technological landscape.

With the in-depth advancement of supply-side structural reforms, digital technology has flourished, rapidly innovated, and penetrated into other economic fields. Based on the existing economic theory, this article analyzes the impact of the digital economy on economic growth from the micro level, the meso level, and the macro level.

The micro-level digital economy (different from the traditional economy, which only emphasizes price and quantity) meets diverse consumer needs through economies of scale and scope of production. The digital economy achieves a dynamic, diverse, and complex balance of supply and demand through precise matching mechanisms [42]. The application of digital technology not only makes it easier for both producers and consumers to achieve economies of scale, resulting in a positive feedback effect and further reducing supply and demand costs. According to Metcalfe's law, the network has strong externalities and positive feedback effects, and the value of the network is proportional to the square of the number of connected users as the number of households connected to the information and communication network increases [43]. With rapid expansion, the network externalities of ICT have gradually emerged. Digital technology improves the original transaction matching efficiency, and it can also realize transactions that could not be completed on the digital technology platform.

At present, the digital economy has shifted from the development of digital technology innovation and integration, the application of digital technology, and the development of industrialization, to the development stage of deep integration of the digital economy and the real economy [44]. The meso-level digital economy has an obvious "enabling effect", which not only realizes the industrialization of digital technology, but also helps to promote the digital, network, and intelligent transformation of traditional industries, to form new models, new industries, and new business formats through industrial integration. Digital technology, as a general purpose technology, has the characteristics of versatility and high permeability, and has natural integration with the real economy [45]. As the consumer internet is extended to industrial internet, integration of the digital economy and the real economy is also expanding, from the consumer sector to the production sector. At present, digital technology has been widely used in the field of industrial manufacturing, giving birth to intelligent manufacturing, personalized customization, networked collaboration, and service-oriented manufacturing models, which have improved the economic efficiency of the entire industrial production sector.

At the macro level, the digital economy mainly affects economic development by affecting production input and output efficiency, which is reflected in the increase in factor input, the improvement of factor allocation efficiency, and the increase of total factor productivity [46]. In the era of the digital economy, factor sources have become more diversified, complicated, and advanced, and the efficiency of factor allocation and utilization is continuously improving. The digital revolution involves the large-scale proliferation and application of information and communication technologies. In other words, the essential feature of the digital economy lie in the application of technological innovation to all aspects of economic life through deep integration of the digital economy and the real economy. According to the general technology theory, digital technology has the characteristics of being widely used, with continuous improvement and stimulating innovation. Digital economy not only directly affects the innovation efficiency of ICT production departments, but also the production efficiency of ICT users through diffusion and spillover effects [47]. 
Empirical research shows that, compared to information technology manufacturing and R\&D departments, information technology application departments, such as finance and retail, have gradually become the main driving forces of productivity growth by increasing investments in information systems. Therefore, based on the analysis of the micro-, meso-, and macro-levels, this article proposes the first research hypothesis.

Hypothesis 1 (H1). The development of the digital economy has a positive effect on urban economic growth.

\subsection{Theoretical Mechanism Analysis}

The digital economy can cultivate more entrepreneurial opportunities by influencing market scale, knowledge spillovers, and factor combinations. It will also enrich entrepreneurial resources by accelerating information interaction and dissemination of ideas, thereby promoting the entrepreneurial activity of cities [48]. First, the development of the digital economy will stimulate the diversified needs of customers for products. The development of the digital economy has transformed the unidirectional output flow of product suppliers into a two-way exchange flow between product suppliers and demanders. The development of the digital economy will stimulate demand for product diversification, promote the growth of product market output and types, and become the basis for entrepreneurial activities. Second, the development of the digital economy will satisfy entrepreneurs' information acquisition needs. The digital economy provides a convenient information exchange platform, which plays an important role in promoting business opportunities before entrepreneurial decision-making or information communication in the entrepreneurial process. Thus, the development of the digital economy provides an information source and information foundation for the decision-making of entrepreneurial activities [49]. Third, the development of the digital economy will optimize and accelerate product matching and transactions. The expansion of product scale and the diversification of product types have produced richer information; information redundancy has made the economic system more complicated and brought new matching problems. In this process, emerging technologies, such as the internet, cloud computing, and big data have provided an optimized path for matching problems in the economic market. Thus, the development of the digital economy provides a solid background support for entrepreneurial activities [50]. In addition, the digital economy has strong social interaction, which will not only promote the accumulation of social capital, but will also further strengthen the demonstration effects of the successful formation of entrepreneurship, thereby having an impact on surrounding entrepreneurship.

Moreover, the increase in entrepreneurial activities contributes to economic growth [51]. Entrepreneurship is the internal vitality of economic growth, which has an important impetus to high-quality development content, such as job creation, and helps change the traditional growth model of "high investment, high energy consumption, and high pollution" [52,53]. The internet, especially in terms of achieving shared development, can increase the entrepreneurial probability of families with low social capital, and promote economic growth in China by promoting equalization of entrepreneurial opportunities. While promoting entrepreneurial activities, the continuous diffusion and widespread penetration of the digital economy in various social and economic fields has made it easier for entrepreneurs to obtain efficient innovation resources [54]. This role promotes the production and collision of innovative thinking, and improves the commercialization capabilities of new technologies, thereby releasing the innovation spillover dividends of the Internet in the application sector, and providing new momentum for the construction of innovation-driven economic development. Therefore, based on the above theoretical analysis, this article proposes the second research hypothesis.

Hypothesis 2 (H2). The development of the digital economy promotes urban economic growth by promoting urban entrepreneurship. 


\subsection{Theoretical Analysis of Spatial Spillover Effects}

As a new engine of economic growth, the digital economy has become increasingly important for regional economic structural upgrading and coordinated development [55]. The development of the digital economy has realized the two-way information flow between enterprises and markets, and between enterprises and enterprises, resulting in different paths and varying degrees of spillover effects [56]. With the continuous increase of economic linkage between regions, the interactive effects between different regions gradually appear. The economic growth level of one region may also be affected by the economic growth level of other regions, resulting in spatial autocorrelation. At the same time, the digital economy uses modern information networks as an important carrier, and uses digital knowledge and information as key production factors [57]. With its own characteristics of permeability, integration, and synergy, it can break through the limitations of geographic distance. It can transcend the constraints of space and region, achieve cross-regional division of labor and cooperation, and produce spatial spillover effects, and then the development level of the digital economy in this region can also affect the economic growth level of other regions.

The spatial spillover effect mechanism of the digital economy is mainly divided into two aspects: on the one hand, from the perspective of resource allocation, the digital economy accelerates regional industrial structure optimization and promotes regional economic growth through technological spillovers; on the other hand, from the perspective of knowledge producers, it can be seen that the digital economy promotes the coordinated development of industries through inter-regional knowledge spillovers to promote regional economic growth [58].

In terms of increasing productivity, the New Economic Growth Theory indicates that the increase in $R \& D$ investment and knowledge stock can improve innovation capabilities, promote productivity in the region, and accelerate regional economic growth. While human capital improves the productivity of investors, it will also produce external effects, that is, knowledge spillover effects, which will eventually lead to increasing returns to scale of production [59]. Therefore, based on the above theoretical analysis, this article proposes the third research hypothesis.

Hypothesis 3 (H3). The development of a digital economy has a "spatial spillover effect" on urban economic growth.

\section{Research Design}

\subsection{Empirical Model}

Based on the above literature analysis, in order to study the influence of digital economy development on economic growth, the following model is set for empirical analysis [60]:

$$
E G_{i t}=\alpha+\beta D E I_{i t}+\sum_{i} \beta_{i} X_{i t}+\mu_{i}+\delta_{t}+\varepsilon_{i t}
$$

where $i$ is the city, $t$ is the year. $E G_{i t}$ is the explained variable. $E G_{i t}$ refers to economic growth. $D E I_{i t}$ is the explanatory variables. $D E I_{i t}$ refers to the development of the digital economy. $\beta$ is the regression coefficient. If the $\beta$ is significantly negative, it means that the development of the digital economy can promote economic growth; if the regression coefficient $\beta$ is significantly positive, it means that the development of the digital economy restrains economic growth. $X_{i t}$ is a series of control variables. $\mu_{i}, \delta_{t}$ is the fixed effect of city and time, and $\varepsilon_{i t}$ is the error term.

\subsection{Exogenous Shock Analysis}

In view of the exogenous characteristics of government policies and the possible differences in the impact of government policies on various cities in China, cities in the eastern region were used as the control group, and cities in the central and western regions were used as the experimental group to study the impacts of the development of a digital economy on cities in the central and western regions. The 2013 "Notice of the State Council 
on issuing the "Broadband China" Strategy and Implementation Plan" and the "G20 Digital Economy Development and Cooperation Initiative" proposed at the 2016 G20 Summit were taken as external policy shocks, and this paper adopted the Double Difference Method (DID) to study the policy effects of the development of the digital economy [61]. The specific model is as follows:

$$
E G_{i t}=\alpha+\beta D E P_{i t}+\sum_{i} \beta_{i} X_{i t}+\mu_{i}+\delta_{t}+\varepsilon_{i t}
$$

where $i$ is the city, $t$ is the year, the core explanatory variable, national digital economy policy is set as a dummy variable $D E P_{i, t}=$ treatment $_{i} *$ post $_{t}$, where treatment $t_{i}$ is whether the city is an central or west city; if so, it is 1 , otherwise 0 ; post $t_{t}$ is a time dummy variable, and whether the year is before the implementation of "Broadband China" in 2013; if so, it is 0, otherwise 1. It is recorded as 0 before the launch of the "G20 Digital Economy Development and Cooperation Initiative" in Hangzhou, China, in 2016, otherwise it is recorded as 1 . The meanings of other variables are consistent with Formula (1).

\subsection{Mechanism Analysis}

Based on the above theoretical analysis, in order to analyze the mechanism of the development of the digital economy on economic growth, the mediation effect model is used for empirical research [62]. The specific model is as follows:

$$
\begin{gathered}
R E_{i t}=\alpha+\beta D E I_{i t}+\sum_{i} \beta_{i} X_{i t}+\mu_{i}+\delta_{t}+\varepsilon_{i t} \\
E G_{i t}=\alpha+\beta D E I_{i t}+\gamma_{1} R E_{i t}+\sum_{i} \beta_{i} X_{i t}+\mu_{i}+\delta_{t}+\varepsilon_{i t}
\end{gathered}
$$

where $R E_{i t}$ represents urban entrepreneurship, $D E I_{i t}$ represents the development of the digital economy, $E G_{i t}$ indicates economic growth, the meanings of other variables are consistent with Formula (1).

\subsection{Endogenous Problems}

In order to avoid endogenous problems and possible two-way causality, the per capita post and telecommunications business and fixed telephone penetration rate were selected as instrumental variables for the development of the digital economy to perform empirical regression, which not only met the requirements of the "correlation" between instrumental variables and explanatory variables, but also met instrumental variables and "exclusivity" requirements with other variables.

\subsection{Spillover Analysis}

In order to measure the spillover effect of the urban digital economy development on economic growth in China, the adjacent matrix and the inverse distance matrix will be used to conduct empirical analysis of three spatial measurement models, namely the spatial error model (SEM), the spatial lag model (SAR) and the spatial Durbin model (SDM) [63].

SEM model:

$$
\begin{gathered}
E G_{i t}=\alpha+\beta D E I_{i t}+\sum_{i} \beta_{i} X_{i t}+\alpha_{i}+v_{i}+\tau_{i t} \\
\tau_{i t}=\gamma W \tau_{i t}+\varepsilon_{i t}
\end{gathered}
$$

SAR model:

$$
E G_{i t}=\alpha+\rho W * E G_{i t}+\beta D E I_{i t}+\sum_{i} \beta_{i} X_{i t}+\alpha_{i}+v_{i}+\tau_{i t}
$$

SDM model:

$$
E G_{i t}=\alpha+\rho W * E G_{i t}+\beta D E I_{i t}+\theta W * X_{i t}+\alpha_{i}+v_{i}+\tau_{i t}
$$


where $W$ is the spatial weight, $\rho$ represents the spatial correlation coefficient. $\alpha_{i}$ is the fixed effects, $v_{i}$ is the random effects, $\varepsilon_{i t}, \tau_{i t}$ are the error terms, the meanings of other variables are consistent with Formula (1).

\subsection{Variable Definition and Data Source \\ 4.6.1. Dependent Variable}

Economic growth (EG). Taking into account the imbalance and insufficiency in China's economic development, the use of per capita GDP can better reflect the economic development of each city, so the actual per capita GDP is used to represent the urban economic growth status, and the variables are processed in logarithms.

\subsubsection{Explanatory Variables}

Digital economy development (DEI). Considering the availability and comparability of data, this article focuses on representative industry sectors and combines the actual situation of China's city-level digital economy development to construct a comprehensive index system for China's city-level digital economy development. The index system comprehensively reflects the development of a digital economy at the city level in China from the three levels of Internet development, ICT use (digital literacy), and industrial efficiency improvement $[64,65]$. It not only reflects the development of digital technology, but also shows the efficiency improvement of the whole industry. As shown in Table 1, the indicators in this system are all positive-benefit indicators. In order to facilitate the comparison of the development level of urban digital economy, the processing method of the Network Readiness Index (NRI) constructed by Harvard University and the World Economic Forum is to carry out the non-dimensional processing of the various benefit indicators in the system, and use 2011 as the base period. The remaining years are calculated using the following Formula (9).

$$
X_{i t}=\frac{V_{i t}-V_{\min 0}}{V_{\max 0}-V_{\min 0}} * 6+1
$$

where $i$ is the city, $t$ is the year, $X_{i t}$ represents the index value after processing, $V_{i t}$ indicates the original index value before processing, $V_{\max 0}$ is the maximum value of the original indicator in the base period in 2011, $V_{\min 0}$ is the minimum value of the original index in 2011 for the base period.

After the dimensionless processing of the original indicators, taking into account the horizontal progress and vertical parallelism between the indicators in the indicator system, this article refers to the NBI's processing method for indicator weights, and assigns the weights of indicators at each level to determine the After weighting, this article uses the following Formula (10) to calculate the value of the digital economy development index.

$$
D E G_{i t}=\sum_{j=1}^{9} X_{i t} * W_{j}(j=1,2, \ldots, 9)
$$

where $D E I_{i t}$ represents the digital economy development index. $W_{j}$ represents the weight of the indicator. $X_{i t}$ represents the index value after processing. 
Table 1. Comprehensive indicator system of China's digital economy development.

\begin{tabular}{lccc}
\hline Index & Sub-Index & Weight & Property \\
\hline & 1. Internet Development & 0.3333 & + \\
(1) number of Internet users per 100 people & 0.0833 & + \\
(2) computer service and software practitioners & 0.0833 & + \\
(3) total telecom business & 0.0833 & + \\
DEI & (4) number of mobile phone users per 100 people & 0.0833 & + \\
& 2. Digital Literacy & 0.3333 & + \\
& (1) number of students in ordinary higher education schools & 0.1667 & + \\
& (2) number of full-time teachers in ordinary colleges & 0.1667 & + \\
3. Industrial Efficiency & 0.3333 & + \\
& (1) relative labor productivity in primary industry & 0.1111 & + \\
& (2) relative labor productivity of the secondary industry & 0.1111 & + \\
(3) relative labor productivity of the tertiary industry & 0.1111 & + \\
\hline
\end{tabular}

\subsubsection{Mechanism Variable}

With reference to existing research practices, this article uses the number of employees in regional urban individual and private enterprises as a percentage of total employment to represent entrepreneurship. The specific data can be obtained and processed from the "China Urban Statistical Yearbook".

\subsubsection{Control Variable}

Referring to the existing literature, this paper also controls other factors affecting the economic growth at the urban level, including (1) the level of urbanization (UL) is measured by the ratio of the total population to the land area of the municipal area. (2) Fiscal decentralization (FD) is measured by revenue in the budget to the expenditure in the budget. (3) Foreign direct investment (FDI) is measured by the actual use of foreign capital to the regional GDP. (4) Financial development level (FL) is measured by deposit and loan balance of financial institutions to the regional GDP. (5) Industrial structure (ISO) is measured by the proportion of tertiary industry to proportion of secondary industry.

\subsubsection{Data Sources and Summary Analysis}

This paper selects the data of 173 cities above the prefecture level in China from 2011 to 2018 for analysis. The original data of the variables are all from the "China City Statistical Yearbook", which was processed by the author. The sample size was 1384 . Economic growth (EG) and urbanization level (UL) were processed by taking the logarithm; the descriptive statistics of specific variables are shown in Table 2.

Table 2. Descriptive statistics of variables.

\begin{tabular}{cccccc}
\hline Variable & Obs & Mean & Sd & Min & Max \\
\hline Economic Growth & 1384 & 10.6666 & 0.5045 & 9.3238 & 12.2288 \\
Digital Economy Index & 1384 & 2.0989 & 0.7415 & 1.3254 & 10.7273 \\
Regional Employment & 1384 & 0.4993 & 0.1268 & 0.0493 & 0.8824 \\
Fiscal Decentralization & 1384 & 0.5068 & 0.2145 & 0.0877 & 1.5413 \\
Financial Level & 1384 & 2.8560 & 2.1176 & 0.7642 & 20.0198 \\
Foreign Direct Investment & 1384 & 0.0234 & 0.0323 & 0.0000 & 0.7746 \\
Industrial Structure & 1384 & 0.9651 & 0.7148 & 0.2555 & 19.2138 \\
Urbanization Level & 1384 & 5.9700 & 0.7188 & 3.5484 & 7.8816 \\
\hline
\end{tabular}

\section{Results and Discussion}

\subsection{The Overall Impact of the Development of the Digital Economy on Economic Growth}

Taking into account the possible endogenous problems, on the basis of random effects and fixed effects regression, this paper selects the instrumental variable method for regression, as shown in Table 3. In the four models, the development of the digital economy has a positive role in promoting urban economic growth, and the development of the 
digital economy can provide new impetus for the economic growth of the city, which also corresponds to China's current policy of vigorously developing the digital economy. In model (1) and model (2), the signs of the variables of digital economy development (DEI), financial development level (FL), industrial structure upgrading (ISU), and urbanization (UL) are all positive, which indicates that the development of digital economy, achieving a higher level of financial development, upgrading the industrial structure, and expanding the level of urbanization are conducive to achieving urban economic growth. The signs of the fiscal decentralization (FD) and foreign investment (FDI) variables are both negative, which indicates that fiscal decentralization is not conducive to urban economic growth. Foreign investment has not significantly promoted urban economic growth. The possible reasons are as follows: on the one hand, with the increase of foreign investment, urban development is likely to form technological dependence, which leads to a decline in innovation capabilities; on the other hand, foreign investment in some cities in China is scarce, which makes the effect of foreign investment on urban economic development is not significant.

Table 3. Benchmark model regression.

\begin{tabular}{|c|c|c|c|c|}
\hline Variable & Model (1) & Model (2) & Model (3) & Model (4) \\
\hline \multirow[t]{2}{*}{ DEI } & $0.2040 * * *$ & $0.1611 *$ & $0.0049 *$ & 0.0043 * \\
\hline & $(0.0124)$ & $(0.0678)$ & $(0.0021)$ & $(0.0021)$ \\
\hline \multirow[t]{2}{*}{ FD } & -0.0208 & $-0.6190^{* * *}$ & -0.0152 & -0.0136 \\
\hline & $(0.0567)$ & $(0.1136)$ & $(0.0103)$ & $(0.0100)$ \\
\hline \multirow[t]{2}{*}{ FL } & $0.0286^{* * *}$ & $0.0243^{* * *}$ & $-0.0028^{* * *}$ & $-0.0029^{* * *}$ \\
\hline & $(0.0025)$ & $(0.0040)$ & $(0.0004)$ & $(0.0004)$ \\
\hline \multirow[t]{2}{*}{ FDI } & -0.4051 * & -0.3081 & -0.0319 & -0.0320 \\
\hline & $(0.1633)$ & $(0.1661)$ & $(0.0246)$ & $(0.0240)$ \\
\hline \multirow[t]{2}{*}{ ISU } & $0.0490^{* * *}$ & 0.0432 & 0.0020 & 0.0018 \\
\hline & $(0.0074)$ & $(0.0395)$ & $(0.0011)$ & $(0.0011)$ \\
\hline \multirow[t]{2}{*}{ UL } & $0.1394^{* * *}$ & $0.7102 * *$ & 0.0238 & 0.0213 \\
\hline & $(0.0286)$ & $(0.2292)$ & $(0.0155)$ & $(0.0149)$ \\
\hline \multirow[t]{2}{*}{ _Cons } & $9.2979 * * *$ & $6.3004^{* * *}$ & $8.8902^{* * *}$ & $7.3783^{* * *}$ \\
\hline & $(0.1649)$ & $(1.3598)$ & $(0.0932)$ & $(0.0893)$ \\
\hline IV1 & & & $0.3043^{* * *}$ & \\
\hline & & & $(0.0016)$ & \\
\hline IV2 & & & & $\begin{array}{c}0.3054 * * * \\
(0.0015)\end{array}$ \\
\hline Cragg-Donald test & & & 33.72 & 35.66 \\
\hline $\mathrm{N}$ & 1384 & 1384 & 1384 & 1384 \\
\hline Adj. R2 & 0.7061 & 0.6233 & 0.3965 & 0.2734 \\
\hline
\end{tabular}

Note: The $10 \%$ and $5 \%$ thresholds of the Stock-Yogo test are 7.56 and 11.04, respectively. Standard errors in the parenthesis, ${ }^{* * *}, * *$, and ${ }^{*}$ are significant at the levels of $1 \%, 5 \%$, and $10 \%$, respectively.

Model (3) and model (4) are instrumental variable regressions, the instrumental variables are per capita post and telecommunications services and fixed telephone penetration rate. The significance of the instrumental variable coefficient values passed the $1 \%$ significance test. The Cragg-Donald test values are both greater than the Stock-Yogo test threshold, indicating that the two selected instrumental variables are valid and meet the "relevance and exclusivity" condition. The signs of the variables of digital economy development (DEI), industrial structure upgrading (ISU) and urbanization (UL) are all positive, and the signs of the variables of fiscal decentralization (FD), financial development level (FL) and foreign investment (FDI) are negative. Except for the changes in the signs of the financial development level (FL) variables, the signs of the other variables are consistent with model (1) and model (2). On the one hand, China's economic and social development is unbalanced and inadequate, and most of the remote cities in the selected sample have relatively low levels of financial development. On the other hand, financial development in some regions may have a phenomenon of "financial exclusion", which makes urban 
development exist a big difference in the availability of required financial capital. Therefore, based on the above analysis, the research hypothesis (1) is established.

\subsection{Double Difference and Mediation Effect Test}

Through the theoretical analysis, this article will use the Double Difference Method (DID) to study the policy effects of the development of the digital economy. The specific results are shown in Table 4. In model (1), the policy impact is the "broadband China strategy implementation". The regression results show that the Treat ${ }^{*}$ post coefficient passes the $10 \%$ significance test, indicating that the development of the digital economy is beneficial to the economic growth of cities in the central and western regions. In model (2), the policy impact is the "G20 Digital Summit Initiative". The regression results show that the Treat*post coefficient has passed the $1 \%$ significance level test, indicating that the development of the digital economy can significantly promote the economic growth of cities in the central and western regions. This result is not only highly consistent with the previous regression results, but also echoes the policies that have been continuously introduced by the state and local governments to encourage the development of the digital economy in recent years.

Table 4. Double difference and mediation effect test.

\begin{tabular}{ccccc}
\hline \multirow{2}{*}{ Variable } & \multicolumn{2}{c}{ Double Difference } & \multicolumn{2}{c}{ Mediation Effect } \\
& Model (1) & Model (2) & Model (3) & Model (4) \\
\hline Treat*post & $0.0343^{*}$ & $0.2019^{* * *}$ & & \\
DEI & $(0.0194)$ & $(0.0224)$ & & $0.1751^{* * *}$ \\
& & & $(0.0147)$ & $(0.0153)$ \\
RE & & & $0.3127^{* * *}$ \\
& & & & $(0.0669)$ \\
FD & $1.8703^{* * *}$ & $1.9709^{* * *}$ & 0.0121 & $1.5465^{* * *}$ \\
& $(0.0497)$ & $(0.0477)$ & $(0.0207)$ & $(0.0515)$ \\
FL & $0.0216^{* * *}$ & $0.0131^{* *}$ & 0.0029 & $0.0099^{*}$ \\
& $(0.0048)$ & $(0.0047)$ & $(0.0019)$ & $(0.0046)$ \\
FDI & -0.4051 & $-0.6810^{* *}$ & 0.2108 & -0.1592 \\
& $(0.2960)$ & $(0.2880)$ & $(0.1129)$ & $(0.2806)$ \\
ISU & $0.0371^{* *}$ & $0.0323^{*}$ & $0.0178^{* * * *}$ & -0.0089 \\
& $(0.0134)$ & $(0.0131)$ & $(0.0053)$ & $(0.0133)$ \\
UL & $-0.0673^{* * *}$ & $-0.0705^{* * *}$ & -0.0060 & $-0.0916^{* * *}$ \\
& $(0.0139)$ & $(0.0135)$ & $(0.0054)$ & $(0.0134)$ \\
Cons & $10.0205^{* * *}$ & $9.9876^{* * *}$ & $0.5264 * * *$ & $9.8898^{* * *}$ \\
& $(0.0799)$ & $(0.0756)$ & $(0.2967)$ & $(0.0817)$ \\
N & 1384 & 1384 & 1384 & 1384 \\
Adj. R2 & $0.5774^{* *}$ & 0.6004 & 0.3028 & 0.6773 \\
\hline
\end{tabular}

Note: standard errors in the parenthesis, ${ }^{* * *}, * *$, and ${ }^{*}$ are significant at the levels of $1 \%, 5 \%$, and $10 \%$, respectively.

This paper will use the mediation effect model to analyze the path of the influence mechanism, and the specific results are shown in Table 4. In model (3), the dependent variable is urban entrepreneurship, and the variable digital economy development (DEI) coefficient value is 0.4052; in model (4), the dependent variable is economic growth (EG), and the variable digital economic development (DEI) coefficient value is 0.1751 . In both cases, the coefficient value passed the $1 \%$ significance level test, but the variable coefficient value decreased from 0.4052 to 0.1751 , indicating that there is a mechanism that uses "urban entrepreneurship" as an intermediary variable. Therefore, based on the above analysis, the research hypothesis (2) is established.

\subsection{Heterogeneity Test}

Due to the existence of factors, such as differences in resource endowments and geographic location, there is a phenomenon of "inadequate and uncoordinated development" in China's economic and social development. In order to test whether the impact of digital 
economy development on different cities has a heterogeneous effect, this paper will conduct a heterogeneity test of eastern cities, central cities, western cities, and northeastern cities. The regression results are shown in Table 5. In models (1)-(4), the development of digital economy is conducive to urban economic growth, and it is not significant in the western region. The digital economy has a greater effect on the urban economic growth of cities in the central and northeastern regions, the effect on the eastern cities is intermediate, and the effect on the economic growth of western cities is relatively weak. On the one hand, the comprehensive evaluation system for the development of the digital economy consists of three aspects: the development of the Internet, the use of ICT, and the improvement of the efficiency of the entire industry. The development levels of the three aspects in each region are quite different. On the other hand, the development of a digital economy in central and northeastern cities is earlier, deeper, and wider, and the policy effects of digital economic development are also emerging; the eastern region has relatively mature economic and social development, and the dividends of digital economic development released earlier; the level of digital economy development in western cities is relatively low, and the economic growth effects brought about by the development of digital economy have not yet appeared.

Table 5. Heterogeneity test.

\begin{tabular}{ccccc}
\hline Variable & Model (1) & Model (2) & Model (3) & Model (4) \\
\hline Dei & $0.1336^{* * *}$ & $0.2688^{* * *}$ & 0.0419 & $0.2511^{* *}$ \\
Control & $(0.0293)$ & $(0.0750)$ & $(0.0337)$ & $(0.0740)$ \\
_Cons & Yes & Yes & Yes & Yes \\
& $6.4592^{* *}$ & 6.0063 & $8.2548^{* * *}$ & $20.0297^{* * *}$ \\
City & $(2.3139)$ & $(3.0728)$ & $(1.7740)$ & $(3.1590)$ \\
Time & Yes & Yes & Yes & Yes \\
N & Yes & Yes & Yes & Yes \\
Adj. R2 & 456 & 480 & 280 & 168 \\
\hline
\end{tabular}

Note: standard errors in the parenthesis, ${ }^{* * *}$ and ${ }^{* *}$ are significant at the levels of $1 \%$ and $5 \%$, respectively.

\subsection{Spatial Spillover Effect Test}

Before the regression of spatial spillover effects, it is necessary to test the spatial correlation of variables. Moran's I will be used to test the spatial correlation of urban economic growth from 2011 to 2018, and the results are shown in Figure 1. During the sample period, the Moran's I value of urban economic growth all passes the $1 \%$ significance test. Moran's I value presents a dynamic fluctuation trend, which shows that urban economic growth has the characteristics of spatial agglomeration in geographical location.

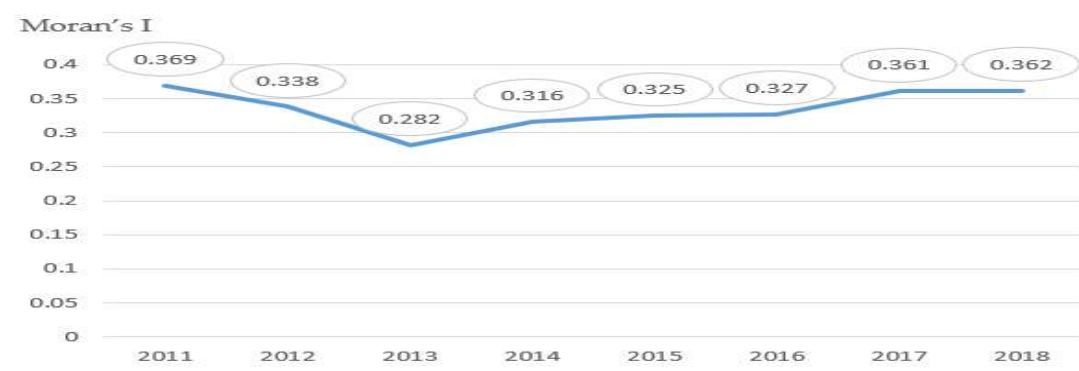

Figure 1. Moran index.

In order to further analyze the spatial agglomeration characteristics of economic growth, this paper will make a Moran index scatter plot, where $I_{i}>0$ indicates that the spatial unit is similar to the neighboring unit in attributes ("high-high" or "low-low"), $I_{i}<0$ means that the spatial unit has the opposite properties of the neighboring unit ("hig-low" or "low-high"). The details are shown in Figure 2. From Figure 2, it can be 
found that most cities exhibited the characteristics of "high-high" and "low-low" spatial agglomeration during the sample period.

Based on the basis of spatial correlation test, in order to better demonstrate the spatial spillover effect of the development of the digital economy on urban economic growth, this paper uses the spatial adjacent $0-1$ matrix and the spatial inverse distance matrix to perform spatial SEM, SAR and SDM regressions in Table 6. In model (1), the digital economy development (DEI) coefficient value and lambda value passed the significance test of $10 \%$ and $1 \%$ respectively. In model (4), the digital economy development (DEI) coefficient value and lambda value passed the significance test of $1 \%$ and $5 \%$ respectively. In models (2)-(3) and models (5)-(6), the digital economy development (DEI) coefficient value and lambda value passed $1 \%$ significance test, and all model coefficient signs are positive, indicating that the development of the digital economy has a positive spatial effect on urban economic growth.

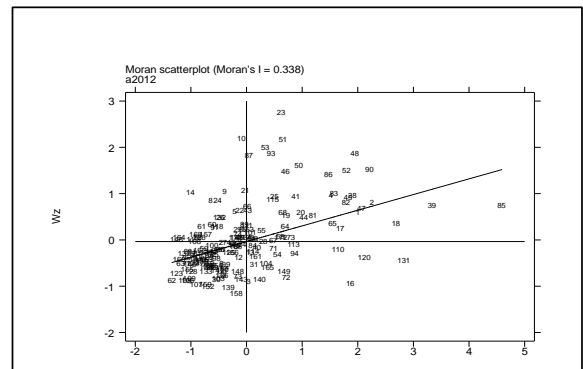

(a)

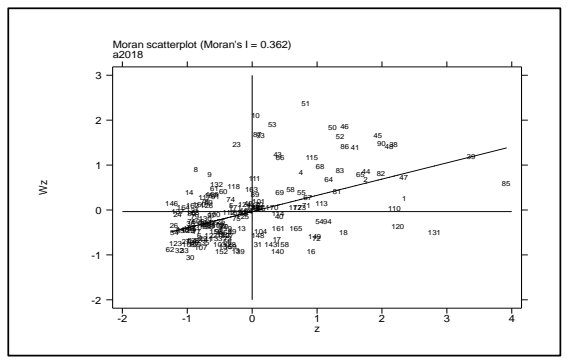

(c)

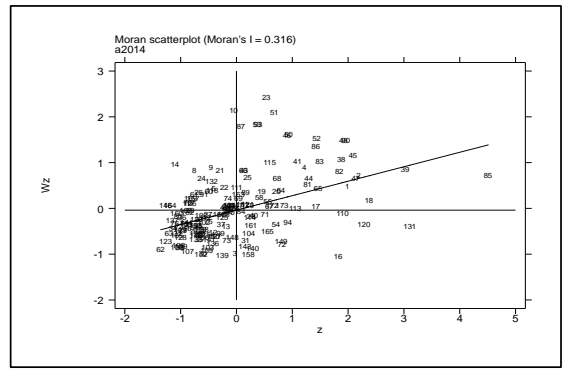

(b)

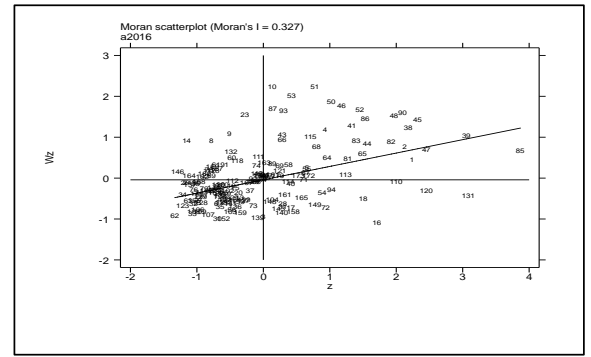

(d)

Figure 2. Moran index scatter plot: (a) 2012; (b) 2014; (c) 2016; (d) 2018.

In models (1)-(6), the direct effects of the regression of each model are greater than the indirect effects, indicating that the development of a digital economy has a more significant role in promoting economic growth in the region. In models (2)-(3), the signs of direct effects, indirect effects, and total effects of digital economy development are all positive, and they all pass the $1 \%$ significance test, indicating that the development of digital economy has a positive spatial spillover effect. In model (5), the signs of the direct effects, indirect effects, and total effects of the digital economy development are all positive, and they all pass the $1 \%$ significance test, which again shows that the development of the digital economy has a positive spatial spillover effect. In model (6), the direct effect coefficient of digital economy development is positive, and the coefficient is significantly reduced; the indirect effect passes the $1 \%$ significance test, and the total effect coefficient is positive. Therefore, vigorously developing the digital economy will not only promote the economic growth of cities in this region, but also have a positive spatial spillover effect on neighboring regions. From the above analysis, the hypothesis (3) holds. 
Table 6. Spatial spillover effect.

\begin{tabular}{|c|c|c|c|c|c|c|}
\hline \multirow{2}{*}{ Variable } & \multicolumn{3}{|c|}{ Adjacency Matrix 0-1 } & \multicolumn{3}{|c|}{ Inverse Distance Matrix } \\
\hline & SEM (1) & SAR (2) & SDM (1) & SEM (4) & SAR (5) & SDM (6) \\
\hline \multirow[t]{2}{*}{ DEI } & $0.0088 *$ & $0.0220^{* * *}$ & $0.0195^{* * *}$ & $0.1332^{* * *}$ & $0.0180 * * *$ & $0.0134^{* * *}$ \\
\hline & $(0.0045)$ & $(0.0032)$ & $(0.0032)$ & $(0.0356)$ & $(0.0037)$ & $(0.0036)$ \\
\hline \multirow[t]{2}{*}{$\mathrm{W}^{*} \mathrm{DEI}$} & & & $0.0169^{* * *}$ & & & 0.1029 \\
\hline & & & $(0.0044)$ & & & $(0.0770)$ \\
\hline \multirow[t]{2}{*}{ Lambda } & $0.9310 * * *$ & $0.8911^{* * *}$ & $0.8652 * * *$ & $0.1558 * *$ & $3.4231 * * *$ & $3.1268 * * *$ \\
\hline & $(0.0153)$ & $(0.0065)$ & $(0.0084)$ & $(0.0582)$ & $(0.0280)$ & $(0.0916)$ \\
\hline \multirow[t]{2}{*}{ Sigma2_e } & $0.0011^{* *}$ & $0.0010^{* * *}$ & $0.0010^{* * *}$ & $0.0647^{* * *}$ & $0.0014^{* * *}$ & $0.0013^{* * *}$ \\
\hline & $(0.0003)$ & $(0.0000)$ & $(0.0000)$ & $(0.0062)$ & $(0.0001)$ & $(0.0000)$ \\
\hline Control & Yes & Yes & Yes & Yes & Yes & Yes \\
\hline \multirow[t]{2}{*}{ Direct } & & $0.1546^{* * *}$ & $0.2121^{* * *}$ & & $0.3732 * * *$ & 0.2823 \\
\hline & & $(0.0223)$ & $(0.0317)$ & & $(0.1002)$ & $(0.1478)$ \\
\hline \multirow[t]{2}{*}{ Indirect } & & $0.0396^{* * *}$ & $0.0448^{* * *}$ & & $0.0207^{* * *}$ & $0.0155^{* * *}$ \\
\hline & & $(0.0056)$ & $(0.0061)$ & & $(0.0042)$ & $(0.0041)$ \\
\hline \multirow[t]{2}{*}{ Total } & & $0.1942^{* * *}$ & $0.2569 * * *$ & & $0.3939 * * *$ & 0.2978 * \\
\hline & & $(0.0277)$ & $(0.0372)$ & & $(0.1031)$ & $(0.1497)$ \\
\hline $\mathrm{N}$ & 1384 & 1384 & 1384 & 1384 & 1384 & 1384 \\
\hline
\end{tabular}

\subsection{Robustness Test}

In order to empirically enhance the reliability of the results, hybrid pool regression, central city regression, non-central city regression, system GMM regression, and tail model regression were used to conduct stability tests. Municipalities directly under the central government, provincial capitals, and sub-provincial cities are central cities, and the rest are non-central cities. The stability test results are shown in Table 7. In models (1)-(5), in the pool regression, non-central city regression, system GMM regression, and tail model regression, the significance level of the variables passed the $1 \%$ significance test in the digital economy development (DEI). The significance level of the variables in the central city regression passes the $10 \%$ significance test. The coefficients in the five models are all positive, indicating that the development of the digital economy has a positive role in promoting urban economic growth.

Table 7. Robustness test.

\begin{tabular}{cccccc}
\hline Variable & Model (1) & Model (2) & Model (3) & Model (4) & Model (5) \\
\hline DEI & $0.1711^{* * *}$ & $0.0468^{*}$ & $0.2714^{* * *}$ & $0.9672^{* * *}$ & $0.2544^{* * *}$ \\
Control & $(0.0154)$ & $(0.0339)$ & $(0.0500)$ & $(0.0001)$ & $(0.0138)$ \\
& Yes & Yes & Yes & No & Yes \\
_Cons & $10.0485^{* * *}$ & $7.3169^{* * *}$ & $6.1292^{* * *}$ & $0.4140^{* * *}$ & $9.1008^{* * *}$ \\
City & $(0.0742)$ & $(1.2460)$ & $(1.8211)$ & $(0.0031)$ & $(0.1597)$ \\
Time & & Yes & Yes & & Yes \\
N & & Yes & Yes & & Yes \\
Adj. R2 & 1384 & 248 & 1136 & 1211 & 1384 \\
\hline
\end{tabular}

Note: standard errors in the parenthesis, ${ }^{* * *}$ and ${ }^{*}$ are significant at the levels of $1 \%$ and $10 \%$, respectively.

\section{Conclusions}

Sustainable economic growth is a critical concern worldwide. The development of a digital economy contributes to sustainable economic growth. Based on domestic and foreign literature reviews, and focusing on representative industries, in this paper, we reviewed digital economy development in China and constructed a 2011-2018 digital economy development index for 173 cities in China, focusing on internet development, digital literacy, and industrial efficiency improvement. This article studies the effect and mechanism of the digital economic development on urban economic growth in China. 
First, in order to avoid endogenous problems and two-way causality, the per capita post and telecommunications business and fixed telephone penetration rate were selected as instrumental variables for the development of the digital economy to perform empirical regression. Second, this paper presented two kinds of policy shocks to study the policy effects of the development of the digital economy through the double difference method (DID). We used the intermediary effect model to study the mechanism of the development of the digital economy on economic growth. Then this article presented a variety of spatial measurement models to verify the spatial spillover effects of the development of the digital economy. Finally, this paper presented hybrid pool regression, central city regression, non-central city regression, system GMM regression, and shrinking model regression to test the model stability, and the stability test results were established. The main research conclusions and recommendations are as follows:

At present, the development of China's digital economy promotes urban economic growth. This paper selects instrumental variables to regress. The regression results are consistent, which is consistent with the fact that various regions have vigorously developed the digital economy in recent years. Therefore, in the period of economic sustainable development, the scale of the digital economy of the city should be enlarged and strengthened, so that it can continuously inject new impetus into urban economic growth.

Moreover, digital economic development on urban economic growth in China is heterogeneous. On a regional analysis, the size and significance of the promotion of the development of the digital economy in different regions are inconsistent, and the order of the stimulative effect is: central, eastern, northeastern, and western. Therefore, when developing the digital economy, China must fully consider the differences in the level of internet development, digital literacy, and industrial efficiency among cities, identify shortcomings in the development of the digital economy, and strive to reduce inter-city differences of the digital divide.

The "mechanism" of digital economic development on urban economic growth in China involves urban entrepreneurship. This paper uses the mediation effect to analyze the mechanism of action. The empirical analysis shows that the development of the digital economy promotes urban economic growth by promoting urban entrepreneurship. Therefore, in the context of striving to achieve high-quality and sustainable economic development in China, China must continue to increase its support for urban entrepreneurship and employment, and strive to solve difficult problems in the process of entrepreneurship and employment, which will not only help improve people's livelihoods, but also contribute to urban economic growth.

Finally, the development of China's digital economy has a "spatial spillover effect" on urban economic growth. This paper uses two spatial weights to analyze multiple spatial measurement models. The results show that the development of the digital economy has a positive direct effect on the economic growth of the region, as well as a positive indirect effect (spillover effect) on neighboring areas. The direct effect is greater than the indirect effect, and the total effect is positive. Therefore, vigorously developing the digital economy not only provides spatial growth momentum for the region, but also helps to promote the economic growth of neighboring regions, and ultimately forms regional coordination and sustainable development. The solutions to these key issues in China require further in-depth research.

Author Contributions: S.J. conceived and designed the study, and performed the analytical model. Q.S. reviewed and edited the paper. Both authors have read and agreed to the published version of the manuscript.

Funding: This research was funded by the Major Project Funding for Social Science Planning Youth Project in Fujian Provincial (grant number FJ2018C041) and the Major Project for the National Social Science Foundation of China (grant number 20XTJ005).

Institutional Review Board Statement: Not applicable.

Informed Consent Statement: Not applicable. 
Data Availability Statement: https:/ / data.cnki.net/Yearbook/Navi?type=type\&code=A (accessed on 10 July 2021).

Conflicts of Interest: The authors declare no conflict of interest.

\section{References}

1. Tapscott, D. The Digital Economy: Promise and Peril in the Age of Networked Intelligence; McGraw-Hill: New York, NY, USA, 1996; pp. $4-15$.

2. Schreyer, P. The OCED Productivity Manual: A Guide to the Measurement of Industry-Level and Aggregate Productivity. Int. Product. Monit. 2001, 2, 37-51.

3. Kim, B.; Barua, A.; Whinston, A. Virtual Field Experiments for a Digital Economy: A New Research Methodology for Exploring an Information Economy. Decis. Support Syst. 2002, 32, 215-231. [CrossRef]

4. Banhidi, Z.; Dobos, I.; Nemeslaki, A. What the Overall Digital Economic and Society Index Reveals: A Statistical Analysis of the DESI EU28 Dimensions. Reg. Stat. 2020, 10, 42-62. [CrossRef]

5. Szeles, M.R.; Simionescu, M. Regional Patterns and Drivers of the EU Digital Economy. Soc. Indic. Res. 2020, 150, 95-119. [CrossRef]

6. Li, Z.Q.; Liu, Y. Research on the Spatial Distribution Pattern and Influencing Factors of Digital Economy Development in China. IEEE Access 2021, 9, 63094-63106. [CrossRef]

7. Herrador-Alcaide, T.C.; Hernandez-Solis, M. Accounting Education through Digital Innovation Networks: A Measurement of Its Impact. Digit. Educ. Rev. 2016, 29, 247-264.

8. Fidan, H. Measurement of the Intersectoral Digital Divide with the Gini Coefficients: Case Study Turkey and Lithuania. Eng. Econ. 2016, 27, 439-451. [CrossRef]

9. Gravili, G.; Benvenuto, M.; Avram, A.; Viola, C. The Influence of the Digital Divide on Big Data Generation within Supply Chain Management. Int. J. Logist. Manag. 2018, 29, 592-628. [CrossRef]

10. Coyle, D.; Nguyen, D. Cloud Computing, Cross-Border Data Flows and New Challenges for Measurement in Economics. Natl. Inst. Econ. Rev. 2019, 249, R30-R38. [CrossRef]

11. Skliarov, V.; Prokopov, O. Industry 4.0 and Digitalization of the National Measurement Standards. J. UK Metro. 2019, 3, 47-56.

12. Fayyaz, S. A Review on Measuring Digital Trade \& E-commerce as New Economic Statistics Products. Int. J. Stat. Econ. 2019, 99, 57-68.

13. Otioma, C.; Madureira, A.M.; Martínez, J. Spatial analysis of urban digital divide in Kigali, Rwanda. GeoJournal 2019, 84, 719-741. [CrossRef]

14. Stavytskyy, A.; Kharlamova, G.; Stoica, E.A. The Analysis of the Digital Economy and Society Index in the EU. Balt. J. Eur. Stud. 2019, 9, 245-261. [CrossRef]

15. Mirolyubova, T.V.; Karlina, T.V.; Nikolaev, R.S. Digital Economy: Identification and Measurements Problems in Regional Economy. Ekon. Reg. 2020, 16, 377-390. [CrossRef]

16. Ahmed, E.M. Modelling Information and Communications Technology Cyber Security Externalities Spillover Effects on Sustainable Economic Growth. J. Knowl. Econ. 2021, 12, 412-430. [CrossRef]

17. Meng, Q.; Li, M. New Economy and ICT development in China. Inf. Econ. Policy 2002, 14, 275-295. [CrossRef]

18. Lopez, F.L.; Nanclares, N.H.; Vaco, C.B. The Digital Divide as a Challenge to the Knowledge Based Society. Rev. Econ. Mund. 2003, 8, 119-142.

19. Antonelli, C. The digital divide: Understanding the economics of new information and communication technology in the global economy. Inf. Econ. Policy 2003, 15, 173-199. [CrossRef]

20. Gibson, C. Digital Divides in New South Wales: A research note on socio-spatial inequality using 2001 Census data on computer and Internet technology. Aust. Geogr. 2003, 34, 239-257. [CrossRef]

21. Van Deursen, A.J.; van Dijk, J.A. The digital divide shifts to differences in usage. New Media Soc. 2014, 16, 507-526. [CrossRef]

22. Karar, H. Algorithmic Capitalism and the Digital Divide in Sub-Saharan Africa. J. Dev. Soc. 2019, 35, 514-537. [CrossRef]

23. Lai, J.; Widmar, N.O.; Bir, C. Eliciting Consumer Willingness to Pay for Home Internet Service: Closing the Digital Divide in the State of Indiana. Appl. Econ. Perspect. Policy 2020, 42, 263-282. [CrossRef]

24. Apriliyanti, I.D.; Kusumasari, B.; Pramusinto, A.; Setianto, W.A. Digital Divide in ASEAN Member States: Analyzing the Critical Factors for Successful E-government Programs. Online Inf. Rev. 2020, 2, 440-460. [CrossRef]

25. Rodicio-Carcia, M.L.; Rios-de-Deus, M.P.; Mosquear-Gonzalez, M.J.; Abilleira, M.P. The Digital Divide in Spanish Student in the Face of the COVID-19 Crisis. Rev. Int. Educ. Para Justicia Soc. 2020, 3, 103-125.

26. Cortelyou-Ward, K.; Atkins, D.N.; Noblin, A.; Rotarius, T.; White, P.; Carey, C. Navigating the Digital Divide: Barriers to Telehealth in Rural Areas. J. Health Care Poor Underserved 2020, 31, 1546-1556. [CrossRef]

27. Murthy, K.V.B.; Kalsie, A.; Shankar, R. Digital Economy in a Global Perspective: Is there a Digital Divide? Transnatl. Corp. Rev. 2021, 13, 1-15.

28. Garcia, K.R.; Rodrigues, L.; Pereira, L.; Busse, G.; Irbe, M.; Almada, M.; Christensen, C.; Midão, L.; Dias, I.; Heery, D.; et al. Improving the digital skills of older adults in a COVID-19 pandemic environment. Educ. Gerontol. 2021, 47, 196-206. [CrossRef]

29. Rallet, A. New Economy and E-commerce: Beyond Measure? In Annales des Telecommunications-Annals of Telecommunications; Presses Polytechniques et Universitaires Romandes: Lausanne, Switzerland, 2003; Volume 58, pp. 147-166. 
30. Venturini, F. The long-run impact of ICT. Empir. Econ. 2009, 37, 497-515. [CrossRef]

31. Tung, R.L. China's leading Internet guru Charles Zhang, chairman of SOHU.com Inc., on how the Internet has changed the world's most populous nation. Acad. Manag. Perspect. 2004, 18, 143-150. [CrossRef]

32. Potts, J. Do developing economies require creative industries? Some old theory about new China. Chin. J. Commun. 2009, 2, 92-108. [CrossRef]

33. Cardona, M.; Kretschmer, T.; Strobel, T. ICT and productivity: Conclusions from the empirical literature. Inf. Econ. Policy 2013, 25, 109-125. [CrossRef]

34. Frey, C.B. The End of Economic Growth? Sci. Am. 2015, 312, 12. [CrossRef]

35. Knight, S. Delivering the digital region: Leveraging digital connectivity to deliver regional digital growth. Aust. Plan. 2015, 52, 4-15. [CrossRef]

36. Chakpitak, N.; Maneejuk, P.; Chanaim, S.; Sriboonchitta, S. Thailand in the Era of Digital Economy: How Does Digital Technology Promote Economic Growth? Artif. Intell. 2017, 753, 350-362. [CrossRef]

37. Martin-Shields, C.P.; Bodanac, N. Peacekeeping's Digital Economy: The Role of Communication Technologies in Post-conflict Economic Growth. Int. Peacekeeping 2018, 25, 420-445. [CrossRef]

38. Hawash, R.; Lang, G. Does the digital gap matter? Estimating the impact of ICT on productivity in developing countries. Eurasian Econ. Rev. 2020, 10, 189-209. [CrossRef]

39. Vu, K.; Hanafizadeh, P.; Bohlin, E. ICT as a driver of economic growth: A survey of the literature and directions for future research. Telecommun. Policy 2020, 44, 101922. [CrossRef]

40. Solomon, E.M.; van Klyton, A. The Impact of Digital Technology Usage on Economic Growth in Africa. Util. Policy 2020, 67, 101104. [CrossRef] [PubMed]

41. Qian, H.; Tao, Y.; Cao, S.; Cao, Y. Theoretical and Empirical Analysis on the Development of Digital Finance and Economic Growth in China. J. Quant. Tech. Econ. 2020, 37, 26-46. (In Chinese)

42. Joegenson, D.W.; Ho, M.S.; Sammuels, J.D. Industry Origins of the American Productivity Resurgence. Econ. Syst. Res. 2007, 19, 229-252. [CrossRef]

43. Kolodynskyi, S.; Drakokhrust, T.; Bashynska, M. The innovative infrastructure of economic development in the framework of international digital transformation. Balt. J. Econ. Stud. 2018, 4, 166-172. [CrossRef]

44. Syuntyurenko, O.V. The Risks of the Digital Economy: Information Aspects. Sci. Tech. Inf. Process. 2020, 47, 104-112. [CrossRef]

45. Baus, S.; Fernald, J. Information and Communications Technology as a General-Purpose Technology: Evidence from Industry Data. Ger. Econ. Rev. 2007, 8, 146-173. [CrossRef]

46. Syuntyurenko, O.V.; Dmitrieva, E.Y. The State System for Scientific and Technical Information within the Objectives of the Digital Economy. Sci. Tech. Inf. Process. 2019, 46, 288-297. [CrossRef]

47. Sitnicki, M.; Netreba, I. Interdependence assessing for networked readiness index economic and social informative factors*. Balt. J. Econ. Stud. 2020, 6, 47-53. [CrossRef]

48. Chen, T.S.; Chou, Y.S.; Chen, T.C. Mining User Movement Behavior Patterns in a Mobile Service Environment. IEEE Trans. Syst. Man Cybern. Part A 2011, 42, 87-101. [CrossRef]

49. Breznitz, S.M.; Noonan, D.S. Arts districts, universities, and the rise of digital media. J. Technol. Transf. 2014, 39, 594-615. [CrossRef]

50. Lapina, M.A.; Shirokovskikh, S.A.; Vernikov, V.A.; Sepiashvili, E.N. Digital Service Economy: Current Trends and Labour Market Effects. Rev. Incl. 2020, 7, 362-373.

51. Matyash, I.V. Investment Attractiveness and Sustainable Growth of Telecommunication Companies: Value-Oriented Approach. Ekon. Reg. 2018, 14, 1411-1423. [CrossRef]

52. Shevelova, S.; Plaskon, S. Is the Ukrainian economy's absorptive capacity appropriate to attract foreign direct investment and facilitate economic growth? Int. J. Emerg. Mark. 2018, 13, 1928-1947. [CrossRef]

53. Na, H.S.; Hwang, J.; Kim, H. Digital content as a fast Internet diffusion factor: Focusing on the fixed broadband Internet. Inf. Dev. 2020, 36, 97-111. [CrossRef]

54. Pavlovich, V.V.; Batrazovna, V.D.; Shamsudinovna, D.M.; Viktorovna, A.Z.; Semenovna, N.S. Digital Economy Features in the Field of State Electronic Services in the Russian Federation. Int. Rev. 2020, 1-2, 11-17. [CrossRef]

55. Aleksandrovna, E.; Vladimirovna, S.; Vladimirovna, O.; Valentinovna, A.; Andreevna, G.; Nikolaevna, K. Features of Development of the Russian Digital Economy. J. Complement. Med. Res. 2020, 11, 56. [CrossRef]

56. Anselin, L.; Bera, A.K.; Florax, R.; Yoon, M.J. Simple diagnostic tests for spatial dependence. Reg. Sci. Urban Econ. 1996, 26, 77-104. [CrossRef]

57. Lin, J.; Yu, Z.; Wei, Y.D.; Wang, M. Internet Access, Spillover and Regional Development in China. Sustainability 2017, 9 , 946. [CrossRef]

58. Dong, Z.; Tian, M.; Ding, L. A Framework for Modeling and Structural Vulnerability Analysis of Spatial Cyber-Physical Power Systems from an Attack-Defense Perspective. IEEE Syst. J. 2021, 15, 1369-1380. [CrossRef]

59. Song, Z.; Song, T.; Yang, Y.; Wang, Z. Spatial-Temporal Characteristics and Determinants of Digital Divide in China: A Multivariate Spatial Analysis. Sustainability 2019, 11, 4529. [CrossRef]

60. Beck, T.; Levine, R.; Levkov, A. Big Bad Banks? The Winners and Losers from Bank Deregulation in the United States. J. Financ. 2010, 65, 1637-1667. [CrossRef] 
61. Nunn, N.; Qian, N. The Potato's Contribution to Population and Urbanization: Evidence from a Historical Experiment. Q. J. Econ. 2011, 126, 593-650. [CrossRef]

62. Velasco-Fernández, R.; Dunlop, T.; Giampietro, M. Fallacies of energy efficiency indicators: Recognizing the complexity of the metabolic pattern of the economy. Energy Policy 2020, 137, 111089. [CrossRef]

63. Eaton, J.; Eckstein, Z. Cities and growth: Theory and evidence from France and Japan. Reg. Sci. Urban Econ. 1997, $27,443-474$. [CrossRef]

64. Sarangi, A.K.; Pradhan, R.P. ICT infrastructure and economic growth: A critical assessment and some policy implications. Decision 2020, 47, 363-383. [CrossRef]

65. Chaliuk, Y.; Dovhanyk, N.; Kurbala, N.; Komarova, K.; Kovalchuk, N. The Digital Economy in a Global Environment. Ad Alta-J. Interdiscip. Res. 2021, 11, 143-148. 